\title{
Effects of (+)-S-Abscisic Acid on the Quality of Stored Cucumber and Tomato Seedlings
}

\author{
Hiroko Yamazaki, Takaaki Nishijima, and Masaji Koshioka \\ National Research Institute of Vegetables, Ornamental Plants and Tea, 360 \\ Kusawa, Ano, Mie 514-23, Japan
}

Additional index words. stem elongation, transpiration, high temperature, Cucumis sativus, Lycopersicon esculentum

Abstract. Effects of ABA on the quality of stored cucumber (Cucumis sativus L.) and tomato (Lycopersicon esculentum Mill.) seedlings were investigated in two experiments. Foliarly applied ABA ( 20, 100, or $500 \mathrm{mg} \cdot \mathrm{liter}^{-1}$ ) decreased transpiration of stored, pot-grown, cucumber seedlings at 8,15 , and $20 \mathrm{C}$. Seedlings stored at 15 and $20 \mathrm{C}$ were slender with long internodes. At these temperatures, $\mathrm{ABA}$ at 100 and $500 \mathrm{mg}^{-1 i t e r}{ }^{-1}$ reduced plant internode length. Seedlings stored at $8 \mathrm{C}$ and those not stored were short, and $\mathrm{ABA}$ did not affect internode length. A decrease of chlorophyll content in the first leaf of seedlings stored at $20 \mathrm{C}$ was less pronounced with $\mathrm{ABA}$. In the second experiment, the effect of a foliar ABA application on stored, plug-grown, cucumber and tomato seedlings was determined. When seedlings were stored at $20 \mathrm{C}$, those sprayed with $\mathrm{ABA}$ did not wilt, but nontreated seedlings did wilt. No seedlings wilted when stored at 8 and 15C. These results suggest that ABA could be used to maintain the quality of cucumber and tomato seedlings stored at 15 or 20C. Chemical name used: (+)-S-abscisic acid (ABA).

Seedling quality is highly valued in Japanese vegetable production. Although Japanese vegetable growers previously have grown their own seedlings, commercial seedling production is becoming more prevalent. However, there are problems in supplying growers with high-quality seedlings in commercial seedling production. It is difficult to coordinate plant growth with shipping date, and seedling quality decreases in transit. Seedling storage is a useful technique to solve such problems. Low-temperature storage is desirable in tomato and bedding plant seedlings (Petunia $\times$ hybrida Vilm., Viola $\times$ wittrockiana Gams, and Salvia splendens F. Sellow ex Roem. \& Schult); high-temperature storage increases plant height, turns leaves yellow, and decreases transplant survival (Kaczperski and Armitage, 1992; Risse et al., 1979, 1985). In addition, because commercial seedlings often are grown in small soil volumes, they may wilt if stored at high temperatures. However, if seedlings could be stored at high temperatures and retain the same quality as those stored at low temperatures, temperature control would not be needed to store seedlings.

ABA induces stomatal closure, resulting in decreased transpiration (Mansfield and Jones, 1971; Mittelheuser and Van Steveninck, 1969). Jones and Mansfield (1972) indicated that ABA reduced transpiration in barley (Hordeum vulgare $\mathrm{L}$.) leaves without reducing dry weight accumulation, and they recommended ABA

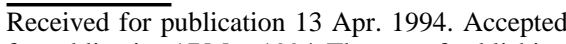
for publication 17 May 1994. The cost of publishing this paper was defrayed in part by the payment of page charges. Under postal regulations, this paper therefore must be hereby marked advertisement solely to indicate this fact. as an antitranspirant. Applying ABA to bell pepper (Capsicum annuum L.) seedlings immediately before transplanting reduced transplant shock and increased yield (Berkowitz and Rabin, 1988). Arteca et al. (1985) indicated that ABA reduced transpiration and photosynthesis and had the potential to reduce shipping injury in geranium (Pelargonium $\times$ hortorum Syn. Bruni) cuttings. However, ABA has not been evaluated as an antitranspirant for stored seedlings. ABA may maintain the quality of seedlings stored at high temperatures by preventing transpiration. Our study was conducted to determine the effect of ABA on transpiration of cucumber and tomato seedlings stored at various temperatures and to examine ABA's ability to maintain the quality of seedlings stored at high temperatures.

\section{Materials and Methods}

Effect of ABA on transpiration (Expt. 1). 'Ohgonmegami no. 2' cucumber seeds were sown in a petri dish, lined with moistened filter paper, and incubated at 30C in darkness for 2 days to hasten germination. Seedlings were grown in plastic pots $\left(90 \mathrm{~cm}^{3}\right)$ in a glasshouse under natural daylength. The pots were filled with commercial soil for cultivation of vegetable seedlings (Kenbyokun no. 2; Otsuka Industry, Nagano, Japan) that consisted of soil, organic matter, inorganic soil conditioner, and (in g.liter ${ }^{-1}$ ) $0.07 \mathrm{~N}-1.2 \mathrm{P}-0.08 \mathrm{~K}$ fertilizer. Windows of the glasshouse automatically opened when the air inside was $>25 \mathrm{C}$; its minimum was maintained at $\geq 15 \mathrm{C}$. At the oneleaf stage, $\approx 0.5 \mathrm{ml} \mathrm{ABA}$ (Hokko Chemical Co., Tokyo) at 20, 100, or $500 \mathrm{mg} \cdot$ liter $^{-1}$ was sprayed on each seedling; nothing was sprayed on control seedlings. Twenty-four hours after spraying, seedlings were packed in boxes and transferred to dark rooms at 8,15 , or $20 \mathrm{C}$ (relative humidity, $80 \%$ to $90 \%$ ) for 10 days. The pots were weighed daily during storage. The decrease in pot weight was used as an estimate of transpiration. The pots were covered with vinyl film to prevent water loss from the soil surface. A preliminary experiment showed covering a pot with vinyl film did not affect either shoot or root growth of cucumber seedlings during 10 -day storage at 8,15 , or 20C. The length of the second internode (between the first and second leaves) was measured on the sixth storage day. Chlorophyll content of the first leaf was measured on the 10th storage day only in seedlings stored at 20C, according to Arnon's (1949) procedure.

Effect of ABA on stored, plug-grown seedlings (Expt. 2). Seeds of 'Ohgonmegami no. 2' cucumber and 'Magokoro' tomato were prepared as previously described. Cucumber and tomato seedlings were grown in plug trays with $72\left(28.5 \mathrm{~cm}^{3}\right.$ per cell $)$ and $128\left(24.5 \mathrm{~cm}^{3}\right.$ per cell) inverted pyramid cells per tray, respectively, in a glasshouse under natural daylength. Cells were filled with the same commercial soil and the environment in the glasshouse was controlled as in Expt. 1. At the one-leaf stage for cucumber and the two-leaf stage for tomato, $\approx 0.5 \mathrm{ml}$ of ABA at 20,100 , or $500 \mathrm{mg} \cdot$ liter $^{-1}$ was sprayed on each seedling as in Expt. 1. Nothing was sprayed on control seedlings. Twenty-four hours after spraying, seedlings were packed in boxes and transferred to dark rooms at 8,15 , or $20 \mathrm{C}$. Wilted seedlings were counted and water content of soil sampled from seedlings stored at 20C was measured on the eighth and the fifth storage day for cucumber and tomato, respectively. Seedlings not completely turgid were defined as wilted. Dry weight of soil was obtained after drying at $105 \mathrm{C}$ for 3 days, and the water content was expressed as a percentage of fresh weight.

\section{Results and Discussion}

Effect of ABA on transpiration (Expt. 1). ABA at 20, 100, or $500 \mathrm{mg} \cdot$ liter $^{-1}$ decreased transpiration of cucumber seedlings in storage at 8,15 , or $20 \mathrm{C}$. Transpiration of seedlings stored at 8,15 , or $20 \mathrm{C}$ and treated with $\mathrm{ABA}$ at $500 \mathrm{mg} \cdot \mathrm{liter}^{-1}$ was $43 \%, 66 \%$, and $71 \%$ of nontreated seedlings, respectively, after 10 storage days (Fig. 1A). Transpiration of seedlings stored at $8 \mathrm{C}$ tended to decrease with increasing ABA concentrations; in 20C storage, $\mathrm{ABA}$ reduced transpiration to almost the same extent, regardless of its concentration (Fig. 1A). Seedling transpiration tended to increase with increasing storage temperature, possibly caused by increase of vapor pressure deficit with increasing storage temperature.

Seedlings stored at 15 or $20 \mathrm{C}$ were slender with long internodes. At these temperatures, ABA at 100 and $500 \mathrm{mg}$ liter ${ }^{-1}$ significantly decreased internode length with increasing concentrations (Fig. 1B). However, seedlings stored at $8 \mathrm{C}$ and those grown in a glasshouse without storage were short, and $\mathrm{ABA}$ did not affect internode length (Fig. 1B). This result 
suggests that $\mathrm{ABA}$ inhibits stem elongation only when seedlings are kept in darkness at high temperatures where etiolation occurs.

During 20C storage, ABA-treated seedlings retained significantly more leaf chlorophyll than nontreated seedlings (Table 1). ABA at 20,100, and $500 \mathrm{mg}^{-1 i t e r^{-1}}$ inhibited chlorophyll degradation about equally. However, chlorophyll content of nontreated seedlings before storage was twice that measured after storage (Table 1). The inhibition of chlorophyll degradation by ABA was small compared to chlorophyll degradation in storage.

Effect of ABA on stored, plug-grown seedlings (Expt. 2). When seedlings were stored at 20C, ABA-treated cucumber and tomato seedlings did not wilt, but nontreated seedlings did (Fig. 2, Table 2). Water was applied to cucum- ber and tomato seedlings before storage, and the soil in a plug tray was moistened fully at the start of storage, when the water content was $\approx 48 \%$. The water content of soil sampled from ABA-treated seedlings was significantly higher than that sampled from nontreated seedlings at the end of 20C storage, although water in the soil was lost during storage (Table 2). This result suggests that transpiration inhibition by ABA reduced soil water loss, resulting in inhibition of wilting in plug-grown seedlings stored at 20C. Regardless of ABA treatment, no sign of wilting was observed in cucumber and tomato seedlings stored at 8 or $15 \mathrm{C}$.

Transpiration of pot-grown cucumber seedlings was reduced by ABA at $>20 \mathrm{mg} \cdot \mathrm{liter}^{-1}$, but $>100 \mathrm{mg}$ liter $^{-1}$ was necessary to inhibit internode elongation of cucumber seedlings.
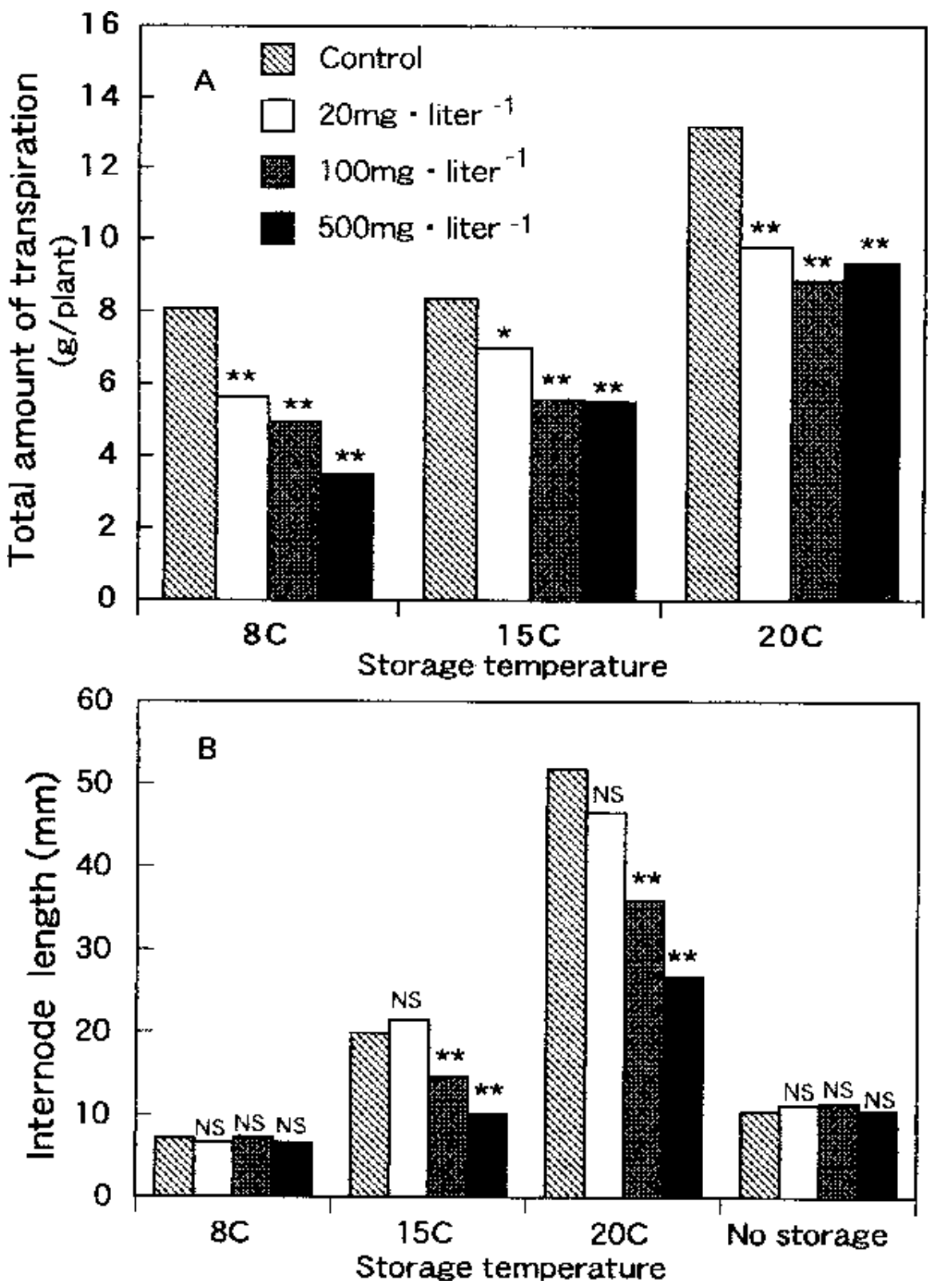

Fig. 1. Effect of ABA on transpiration and internode length of stored cucumber seedlings. (A) Total amount of transpiration of cucumber seedlings stored at 8,15 , or $20 \mathrm{C}$ for 10 days. (B) Length of the second internode of cucumber seedlings stored at 8,15 , or $20 \mathrm{C}$ for 6 days and without storage. Ns, *, ${ }^{* *}$ Nonsignificant or significant by Dunnett's test at $P \leq 0.05$ or 0.01 , respectively.
Thus, higher ABA application was necessary to inhibit elongation than transpiration. At 20C, ABA decreased transpiration of potgrown cucumber seedlings to almost the same extent, regardless of concentration, but it inhibited elongation with increasing concentration. This result suggests elongation inhibition by ABA may not be caused by transpiration inhibition, and the two effects of ABA may be independent. The effect of ABA on growth inhibition depended on growing conditions. For example, ABA suppressed internode elongation of pot-grown cucumber seedlings stored at 15 and $20 \mathrm{C}$, but it did not influence seedlings stored at $8 \mathrm{C}$ or those grown in a glasshouse without storage. In this respect, we consider growth inhibition by ABA to be different from growth inhibition by other growth retardants such as $(E)$-1-(4-chlorophenyl)-4,4dimethyl-2-(1,2,4-triazol-1-yl)-1-penten-3-ol (uniconazole) and (2RS, 3RS)-1-(4chlorophenyl)-4,4-dimethyl-2-(1H-1,2,4triazol-1-yl)pentan-3-ol (paclobutrazol), which produce effects regardless of environment (Fletcher et al., 1986).

ABA promotes chlorophyll degradation in leaf disks (Back and Richmond, 1971) and accelerates senescence. However, ABA inhibited chlorophyll degradation when seedlings were stored at 20C, although the extent of the inhibition was small (Table 1). The conditions in which this action was observed were limited, and, to our knowledge, there has been no examination of ABA's effect on chlorophyll content in stored seedlings. Mizrahi et al. (1974) reported ABA retarded chlorophyll degradation in barley seedlings exposed to drought. The effect of ABA on chlorophyll degradation may depend on plant condition before ABA treatment.

Risse et al. (1979) evaluated tomato transplant qualities after storage at five temperatures (from 4.4 to 21.1C) and showed temperatures between 10 to $12.8 \mathrm{C}$ were best for storage. The main problems under high storage temperatures are increased plant height and decreased leaf chlorophyll content and survival ratio. At first, we anticipated ABA's effect as an antitranspirant when we attempted to use it in high-temperature storage, and ABA reduced transpiration and inhibited wilting during storage as expected. Furthermore, ABA had other effects, notably inhibition of stem elongation and chlorophyll degradation.

The effect of ABA as an antitranspirant in practical experiments has been varied. ABA

Table 1. Effect of ABA treatment on chlorophyll content in the first leaves of cucumber seedlings stored at 20C for 10 days.

\begin{tabular}{lll}
\hline \hline $\begin{array}{l}\text { ABA concn } \\
\left(\mathrm{mg} \cdot l i t e r^{-1}\right)\end{array}$ & \multicolumn{2}{c}{ Chlorophyll $(\mathrm{mg} / \mathrm{g}$ fresh wt) } \\
\cline { 2 - 3 } & $\mathrm{a}$ & $\mathrm{b}$ \\
\hline Control & 0.48 & 0.14 \\
20 & $0.58^{*}$ & $0.18^{*}$ \\
100 & $0.56^{\mathrm{NS}}$ & $0.18^{*}$ \\
500 & $0.57^{*}$ & $0.17^{\mathrm{Ns}}$ \\
Control $^{\mathrm{z}}$ & 1.01 & 0.39 \\
\hline
\end{tabular}

${ }^{\mathrm{z}}$ Not stored.

NS, *Nonsignificant or significant by Dunnett's test at $P \leq 0.05$, respectively. 


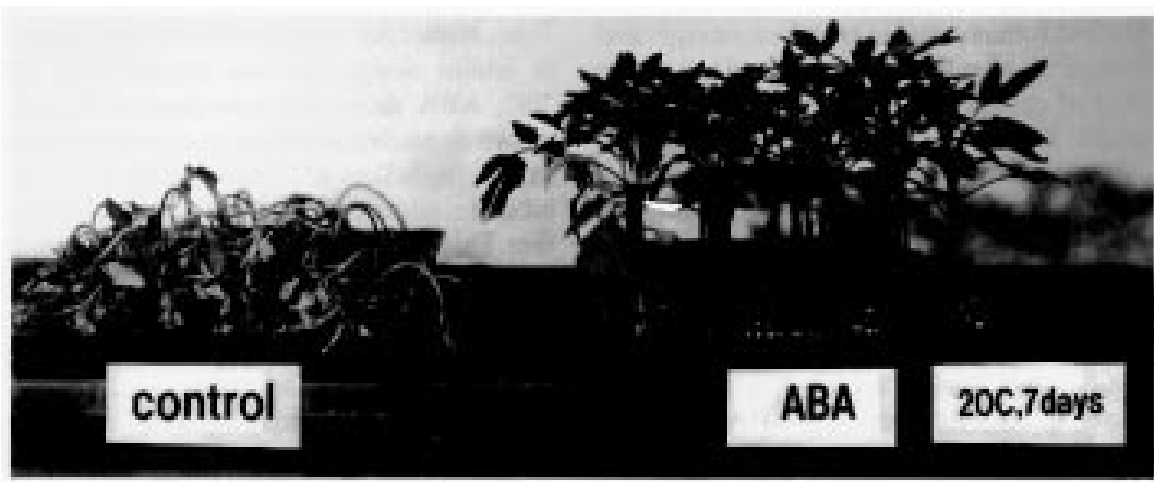

Fig. 2. Tomato seedlings stored at $20 \mathrm{C}$ for 7 days (left) without ABA treatment or (right) treated with 500 mg ABA/liter.

reduced transplant shock in bell pepper seedlings (Berkowitz and Rabin, 1988) and reduced shipping injury in geranium cuttings (Arteca et al., 1985). However, Kramer (1983) concluded that antitranspirants had only limited practical usefulness. Our results indicate that this effect of ABA may depend on the plant species involved and the conditions under which ABA is applied. Thus ABA may be used effectively to improve the quality of stored cucumber and tomato seedlings, particularly at $>15 \mathrm{C}$.

\section{Literature Cited}

Arnon, D.I. 1949. Copper enzymes in isolated chloroplasts. Phenoloxidase in Beta vulgaris. Plant Physiol. 24:1-15.

Arteca, R.N., D. Tsai, and C. Schlagnhaufer. 1985. Abscisic acid effects on photosynthesis and transpiration in geranium cuttings. HortScience 20:370-372.

Back, A. and A.E. Richmond. 1971. Interrelations between gibberellic acid, cytokinins and abscisic acid in retarding leaf senescence. Physiol. Plant. 24:76-79.

Berkowitz, G.A. and J. Rabin. 1988. Antitranspirant associated abscisic acid effects on the water relations and yield of transplanted bell peppers. Plant Physiol. 86:329-331.

Fletcher, R.A., G. Hofstra, and J. Guo. 1986. Comparative fungitoxic and plant growth regulating properties of triazole derivatives. Plant Cell Physiol. 27:367-371.

Jones, R.J. and T.A. Mansfield. 1972. Effect of abscisic acid and its esters on stomatal aperture and the transpiration ratio. Physiol. Plant. 26:321-327.

Kaczperski, M.P. and A.M. Armitage. 1992. Shortterm storage of plug-grown bedding plant seedlings. HortScience 27:798-800.

Kramer, P.J. 1983. Water relations of plants. Academic, New York.

Mansfield, T.A. and R.J. Jones. 1971. Effect of abscisic acid on potassium uptake and starch
Table 2. Effects of ABA on plant wilting and water content of soil in tomato and cucumber seedlings stored at $20 \mathrm{C}$ for 5 and 8 days, respectively.

\begin{tabular}{lcc}
\hline \hline $\begin{array}{l}\text { ABA } \\
\text { concn } \\
\left(\mathrm{mg}^{\prime} \text { liter }^{-1}\right)\end{array}$ & $\begin{array}{c}\text { Wilted } \\
\text { plants } \\
(\%)\end{array}$ & $\begin{array}{c}\text { Soil water } \\
\text { content }^{2} \\
(\%)\end{array}$ \\
\hline \multicolumn{3}{c}{ Tomato seedlings } \\
20 & 83.3 & 29.4 \\
100 & 0 & $34.2^{* *}$ \\
500 & 0 & $36.7^{* *}$ \\
& 0 & $39.6^{* *}$ \\
Control & Cucumber seedlings & \\
20 & 100 & 29.1 \\
100 & 0 & $31.5^{* *}$ \\
500 & 0 & $33.1^{* *}$ \\
& 0 & $32.1^{* *}$ \\
\hline
\end{tabular}

Initially $\approx 48 \%$

** Significant by Dunnett's test at $P \leq 0.01$.

content of stomatal guard cells. Planta 101:147158.

Mittelheuser, C.J. and R.F.M. Van Steveninck. 1969. Stomatal closure and inhibition of transpiration induced by (RS)-abscisic acid. Nature 21:281282

Mizrahi, Y., S.G. Scheringes, S.M. Arad, and A.E. Richmond. 1974. Aspects of the effect of ABA on the water status of barley and wheat seedlings. Physiol. Plant. 31:44-50.

Risse, L.A., D.W. Kretchman, and C.A. Jaworski. 1985. Quality and field performance of densely packed tomato transplants during shipment and storage. HortScience 20:438-439.

Risse, L .A., T. Moffitt, and H.H. Bryan. 1979. Effect of storage temperature and duration on quality, survival, and yield of containerized tomato transplants. Proc. Fla. State Hort. Soc. 92:198-200 